\title{
Tecnologias da humildade: participação cidadã na governança da ciência*
}

\section{Sheila Jasanoff**}

Resumo: A partir de teorias recentes sobre a ciência na sociedade, tal como a abordagem do "Modo 2", este artigo argumenta que os governos devem reconsiderar as relações existentes entre tomadores de decisões, experts e cidadãos na gestão da tecnologia. Formuladores de políticas precisam de uma série de "tecnologias da humildade" para avaliar sistematicamente o desconhecido e o incerto. Pontos focais apropriados para essas avaliações modestas são o enquadramento, a vulnerabilidade, a distribuição e o aprendizado.

Palavras-chave: Participação cidadã. Governança da ciência e tecnologia. Expertise. Tecnologias da humildade. Risco.

\section{Technologies of humility: citizen participation in governing science}

Abstract: Building on recent theories of science in society, such as that provided by the the "Mode 2 "framework, this paper argues that governments should reconsider existing relations among decision-makers, experts, and citizens in the management of technology. Policy-makers need a set of 'technologies of humility' for systematically assessing the unknown and the uncertain. Appropriate focal points for such modest assessments are framing, vulnerability, distribution, and learning.

Key-words: Citizen participation. Science and technology governance. Expertise. Technologies of humility. Risk.

\section{Os perigos da previsão}

Muito antes das atrocidades terroristas de 11 de Setembro de 2001, em Nova York, Washington (DC) e Pensilvânia; dos ataques de antraz por meio dos correios; e das guerras lideradas pelos Estados Unidos no Afeganistão e Iraque, sinais mostravam que a habilidade da América de criar e operar vastos sistemas de tecnologia havia ultrapassado sua capacidade de previsão e controle. Em seu "profético" livro, publicado em 1984, o sociólogo Charles Perrow previu uma série de "acidentes normais", os quais lançaram sombras sobre os últimos anos do século XX e os anos seguintes, sendo os mais notáveis o desastre químico de uma fábrica de pesticidas, em Bhopal,
Recebido: 28.01 .19 Aprovado: 01.04.19
* As tradutoras, os tradutores e o revisor agradecem a Springer por autorizar a publicação em português deste texto, bem como a Sheila Jasanoff pelo auxílio nas negociações com a editora.

Tradução: Eric Vieira, Luiz Henrique S. Brandão,Gabriela Oliveira Sabadini, Luana Marinho do Nascimento e Renato Gontijo Paixão, estudantes do curso de ciência sociais da Universidade de Brasília, com exceção de Luiz Henrique S. Brandão, mestrando em história na mesma instituição. Revisão técnica: Tiago Ribeiro

Duarte, professor do Departamento de Sociologia da Universidade de Brasília (UnB), Brasília (DF) Brasil.

\footnotetext{
** Sheila Jasanoff é professora Pforzheimer de estudos sociais da ciência e tecnologia na Escola de Governo John F. Kennedy da Universidade de Harvard. Sua pesquisa examina o papel da ciência e da tecnologia nas estruturas de autoridade
} 
das democracias modernas e foca particularmente no uso da ciência nas tomadas decisão relacionadas a questões legais. Suas publicações nesses temas incluem:

The fifth branch: science advisers as policymakers (Harvard University Press, 1990) e Science at the bar: law, science, and technology in America (Harvard University Press, 1995).

John F. Kennedy School of Government, Harvard University, 79 John F. Kennedy Street,

Cambridge (MA) 02138. <sheila_jasanoff@ harvard.edu>.

1. Um exemplo proeminente da abordagem fundada no cálculo pode ser encontrado em Graham \& Wiener (1995). na Î́dia; a perda do ônibus espacial Challenger, em 1986; e, nesse mesmo ano, o acidente nuclear em Chernobyl, na então União Soviética; a contaminação de suprimentos de sangue com o vírus da Aids; a crise prolongada da "doença da vaca louca"; a perda da nave espacial estadunidense tripulada Columbia, em 2003; e o constrangedor acidente no programa espacial dos Estados Unidos que, apesar de não ter colocado vidas em risco, deixou as lentes do telescópio Hubble embaçadas; e, por fim, a perda dos caros robôs exploradores de Marte (Perrow, 1984). Além disso, devemos adicionar a descoberta do buraco na camada de ozônio, as mudanças climáticas e outros desastres naturais como sinais de ruína. Ocorridos em diferentes épocas e em diferentes contextos políticos, esses eventos ainda assim serviram de aviso coletivo de que as pretensões humanas de controle sobre os sistemas de tecnológicos precisam de uma séria reavaliação.

Enquanto os teóricos americanos frequentemente atribuíram as falhas da tecnologia a erros evitáveis, especialmente das grandes organizações (Perrow, 1984; Vaughan, 1996; Short \& Lee, 1992; Clarke, 1989), alguns analistas europeus sugeriram um cenário mais problemático. Apresentada de modo apaixonado pelo sociólogo alemão Ulrich Beck, a tese da "modernização reflexiva" argumenta que os riscos são endêmicos no modo em que a sociedade contemporânea conduz seus negócios de tecnologia intensiva (Beck, 1992). Avanços técnicos e científicos trazem benefícios inquestionáveis, mas também geram novas incertezas e falhas, com o resultado de que a dúvida constantemente mina o conhecimento e consequências imprevistas confundem a fé no progresso. Além disso, os riscos da modernidade frequentemente atravessam as divisões sociais e operam como grandes igualadores de classes. A riqueza talvez possa aumentar a longevidade e melhorar a qualidade de vida, mas ela não oferece uma proteção garantida contra os danos ambientais das sociedades tecnológicas. Essa observação foi tragicamente confirmada quando o colapso do World Trade Center, em 11 de setembro de 2001, custou três mil vidas sem diferenciar executivos de empresas, analistas do mercado de ações, programadores de computação, secretários, bombeiros, policiais, zeladores, trabalhadores de restaurantes, dentre outros. De forma similar, a derrota em uma guerra coloca em perigo tanto aqueles que têm poder como os que não têm. Em muitos outros contextos, entretanto, a vulnerabilidade permanece relacionada às circunstâncias socioeconômicas, de modo que as desigualdades persistem a partir da habilidade de alguns grupos sociais e indivíduos se defenderem contra o risco.

"Risco", nesse caso, não é uma simples questão de probabilidade que pode ser calculada racionalmente por especialistas e evitado de acordo com a aritmética exata da análise de custo benefício ${ }^{1}$. Na verdade, o risco é parte da condição 
humana moderna, costurado no próprio tecido do progresso. O problema que encaramos urgentemente é como viver democraticamente e em paz sabendo que nossas sociedades estão inevitavelmente "em risco". Questões que são criticamente importantes sobre a gestão dos riscos não podem ser resolvidas apenas por especialistas com suas ferramentas convencionais de previsão. Essas questões não determinam apenas se vamos ficar doentes ou morrer, e sob quais condições isso ocorrerá, mas também quem será afetado e como nós devemos viver com a incerteza e a ignorância. É suficiente, por exemplo, avaliar as consequências da tecnologia, ou deveríamos também avaliar seus objetivos? Como deveríamos agir quando os valores da investigação científica parecem estar em conflito com outros valores sociais fundamentais? Teria nossa habilidade de inovação em determinadas áreas ultrapassado de modo inaceitável o nosso poder de controle?² Será que algumas das nossas tecnologias mais revolucionárias aumentarão as desigualdades, promoverão violência, ameaçarão culturas ou danificarão o meio ambiente? E nossas instituições, sejam elas nacionais ou internacionais, estão preparadas para a tarefa de governar nossas perturbadoras capacidades tecnológicas?

Para responder questões como estas, a gestão das tecnologias deve ir além do modelo de "dizer a verdade para o poder", que um dia pensou articular o conhecimento às ações políticas ${ }^{3}$. De acordo com esse modelo, a contribuição técnica para os problemas políticos deve ser desenvolvida independentemente de influências políticas; a "verdade" então gerada age como restrição, talvez a mais importante, aos exercícios subsequentes de poder político. Os acidentes e problemas do final do século XX, no entanto, colocaram em questão a validade desse modelo - tanto como descrição precisa sobre os modos como os experts se relacionam com formuladores de políticas, quanto como fórmula normativamente aceitável para utilizar conhecimento especializado em sistemas políticos democráticos (Jasanoff, 1990). Há uma crescente consciência de que até a elaboração técnica de políticas precisa tornar-se mais política - ou mais precisamente para serem observadas com maior exatidão em termos de seus fundamentos políticos. Em um leque cada vez mais amplo de escolhas políticas, as culturas tecnológicas devem aprender a complementar as preocupações dos experts em medir os custos e os benefícios das inovações com maior atenção para as políticas de ciência e tecnologia.

De modo encorajador, a necessidade de reforma da gestão da ciência e tecnologia tem sido reconhecida pelas autoridades políticas. No ano de 2000, por exemplo, o Comitê de Ciência e Tecnologia da Câmara dos Lordes do Reino Unido emitiu um relatório sobre ciência e sociedade que começou com a auspiciosa observação de que a relação entre as duas categorias havia alcançado um estágio crítico ${ }^{4}$. Os autores previam consequências prejudiciais para a ciência e tecnologia caso fos-
2. Nunca longe das mentes de filósofos e autores de ficção, essas preocupações também foram articuladas recentemente por Bill Joy, cofundador e cientista chefe da Sun Microsystems. Ver: Joy, Why the future doesn't need us, disponível em: <http://www. wired.com/wired/ archive/8.04/joy. html>.

3. O locus classicus dessa visão sobre as relações certas entre conhecimento e poder está em Price (1965).

4. Reino Unido, Comitê de Ciência e Tecnologia da Câmara dos Lordes Terceiro relatório, ciência e sociedade 2000. Disponível em: <http:// www.parliament. the-stationeryoffice-co.uk/pa/ Id199900/Idselect/ Idsctech/38/3801. htm>. 
* Accountability é um termo em inglês de difícil tradução direta, por isto optamos por mantê-lo no original. O termo se refere, no contexto deste artigo, à possibilidade de a ciência se tornar mais aberta à prestação de contas pública com relação ao conhecimento produzido e a seus impactos na sociedade. Nesse sentido, a accountability está relacionada a uma maior transparência assim como à possibilidade de a ciência ser responsabilizada não apenas por seus sucessos, mas também pelos riscos que produz (nota dos tradutores).

5. Comissão das Comunidades Europeias, Governança europeia: um informe técnico, 2001. Disponível em: <http://europa. eu.int/eur-lex/en/ com2001_0428en01. pdf $>$. Bruxelas, 27 Jul. 2001. se permitido que essas condições persistissem. Essa observação foi amplamente atribuída à experiência britânica com a "doença da vaca louca", mas a crise de confiança perante a gestão da ciência e tecnologia se espalhou de modo significativamente mais amplo. A nota técnica sobre governança, publicada pela União Europeia em 2001, baseou-se nas atividades de um grupo que trabalhou com a "democratização da expertise", cujo relatório prometeu novas diretrizes "sobre a coleta e o uso das recomendações de experts na Comissão, para permitir a accountability*, pluralidade e integridade da expertise utilizada"5. A intensa discussão mundial sobre os riscos, os benefícios e as consequências sociais da biotecnologia, que começou no final da década de 1990, pode ser vista como compartilhamento dessas mesmas preocupações.

Tais iniciativas e debates refletem um novo interesse da parte de cientistas, governos, dentre outros, em criar uma maior accountability na produção e no uso do conhecimento científico. A condução das pesquisas sofreu mudanças que demandam reconhecimento. Como analisado pela teoria do "Modo 2", a atividade científica tem se tornado mais dispersa, dependente do contexto e orientada para problemas específicos. Dadas essas mudanças, preocupações com a garantia da qualidade e confiabilidade da produção científica, refletindo a dominância do modelo de "dizer a verdade para o poder", são agora consideradas como por demais estreitas. As responsabilidades públicas mais amplas da ciência, assim como as mudanças nos modos de produção de conhecimento, exigem novas formas de justificação pública. A accountability pode ser definida de diversas formas, dependendo da natureza e do contexto da atividade científica - por exemplo, em exigências por precauções nas avaliações ambientais ou na demanda por diretrizes bioéticas em relação às novas tecnologias genéticas. Seja qual for sua articulação específica, todavia, a accountability em uma forma ou em outra está sendo vista cada vez mais como critério independente da avaliação de pesquisas científicas e suas aplicações tecnológicas, acrescentando mais preocupações em relação à segurança, eficácia e eficiência econômica.

Mas como ideias de accountability podem ser mapeadas em relações bem enraizadas entre conhecimento e poder ou expertise e políticas públicas? O momento é adequado para reavaliar com seriedade os modelos e as abordagens existentes. Como as instituições têm conceitualizado os papéis de experts, tomadores de decisões e cidadãos em relação aos usos e aplicações do conhecimento? Como deveriam esses entendimentos ser modificados em resposta a três décadas de pesquisa sobre a dimensão social da ciência? Podemos reagir às falhas e incapacidades demonstradas pelas instituições que tomam decisões sem abandonar a esperança por melhorias na saúde, na segurança, no bem-estar e na justiça social? Pode- 
mos imaginar novas instituições, novos processos e métodos de restauração para o campo de ação da governança algumas das questões normativas que foram deixadas de lado na comemoração dos benefícios do progresso tecnológico? Existem meios estruturados para a deliberação e reflexão sobre assuntos técnicos, assim como a análise especializada sobre riscos tem sido cultivada há muitas décadas?

Argumentarei que existe uma necessidade crescente do que passaremos a chamar de "tecnologias da humildade". Estas tecnologias dizem respeito a métodos ou, melhor ainda, a hábitos institucionalizados de pensamento, que tentam lidar com as margens desgastadas da compreensão humana - o desconhecido, o incerto, o ambíguo e o incontrolável. Ao reconhecerem os limites do controle e da previsão, as tecnologias da humildade confrontam de frente as implicações normativas de nossa falta de capacidade de realizar previsões perfeitas. Elas exigem diferentes capacidades de experts e diferentes formas de engajamento entre os experts, os tomadores de decisões e o público com relação àquelas que eram consideradas necessárias nas estruturas de governança da alta modernidade. Elas exigem não apenas mecanismos formais de participação, mas também um ambiente intelectual, no qual cidadãos são encorajados a trazer seus conhecimentos e suas habilidades para ajudar a construir uma resposta para os problemas coletivos. Após uma breve descrição histórica, vou propor um quadro de referência para desenvolver o tema.

\section{O "contrato social" no período pós-guerra}

A necessidade de colaboração entre ciência e Estado, nos Estados Unidos, foi articulada de modo notável não por um cientista social, nem por um sociólogo do conhecimento, mas pelo mais típico expert técnico: Vannevar Bush (1945), distinto engenheiro do Massachusetts Institute of Technology (MIT) e conselheiro presidencial. Ele antecipou a necessidade de mudanças permanentes após a mobilização da ciência e tecnologia durante a Segunda Guerra Mundial. Em 1945, Bush produziu o relatório Ciência - a fronteira sem fim, posteriormente aclamado como tendo desenvolvido as bases para as políticas públicas estadunidenses relacionadas à ciência e tecnologia. Na visão do engenheiro, a ciência deveria receber financiamento do Estado em períodos de paz assim como havia recebido durante a guerra. O controle sobre o empreendimento científico, no entanto, seria transposto das instâncias militares para a comunidade civil. A pesquisa básica, livre da contaminação das indústrias e do governo, prosperaria no ar puro das universidades. Os padrões intelectuais, assim como o direcionamento das pesquisas, seriam estabelecidos pelos cientistas. Bush acreditava que o grande número de resultados que fluíam dos empreendimentos científicos seriam traduzidos em seu devido momento em tecnologias benéficas que contribuiriam para a prosperidade e progresso da nação. Embora 
6. A criação dos Institutos Nacionais de Saúde (NIH), com o intuito de patrocinar pesquisas biomédicas, dividiu as políticas vinculadas à ciência de modo diverso à proposta original de Bush. Em recentes políticas relacionadas à ciência, os orçamentos da NIH se mostram constantemente mais fáceis de se justificar do que os de outros campos científicos. tal modelo de produção científica tenha demorado anos para na prática se concretizar, e ainda assim não foi plenamente efetivado, a Fundação Estadunidense de Ciência (National Science Foundation - NSF) emergiu como a principal responsável pelo financiamento de pesquisa em ciência básica ${ }^{6}$. A permuta entre financiamento governamental e autonomia por descobertas, inovações tecnológicas e pessoal treinado veio a ser conhecida como o "contrato social da ciência" dos Estados Unidos.

O relatório de Bush pouco avançou sobre como a pesquisa básica contribuiria para o desenvolvimento das ciências aplicadas e da tecnologia. O silêncio em si já dizia bastante. Havia muito tempo em que se assumia ser linear e não problemática a passagem do conhecimento fundamental para as suas aplicações O sistema físico que tomou conta da imaginação de formuladores de políticas foi o de transporte tubular: com as inovações tecnológicas proporcionando enormes lucros, considerações mercadológicas eram vistas como suficientes para direcionar a ciência através da tubulação da pesquisa e desenvolvimento de modo a transformá-la em produtos comercializáveis. Os esforços estatais para promover a ciência poderiam então ser restritos ao apoio à pesquisa básica ou "orientada pela curiosidade". Esse esquema, simplista em seu entendimento sobre as conexões entre ciência e tecnologia, não proporcionava um espaço conceitual para se entender o crescente volume de produção científica requerido para apoiar e legitimar as múltiplas empreitadas dos Estados modernos no final do século XX. Em diversos campos de estudo, de políticas ambientais ao mapeamento e sequenciamento do genoma humano, recursos governamentais foram aplicados em pesquisas que desafiam qualquer demarcação entre ciência básica e aplicada. Ainda assim, durante muitos anos após a Segunda Guerra, a distinção entre pesquisa básica e aplicada manteve-se como o parâmetro para se distinguir o trabalho realizado em universidades daquele conduzido em indústrias, estações experimentais agrícolas, laboratórios nacionais e outros locais que se preocupam primariamente com os usos do conhecimento.

Enquanto o "contrato social" manteve sua forte influência, ninguém questionou se salvaguardar a autonomia dos cientistas era a melhor forma para garantir a qualidade e produtividade da pesquisa básica. A revisão por pares era o instrumento utilizado pelos cientistas para a autorregulação, assim como para o controle de qualidade. Isto assegurou que a pesquisa financiada pelo Estado fosse consistente em relação às prioridades, às teorias e aos métodos de determinada disciplina. A revisão por pares foi responsável, com graus variados de êxito, por garantir a credibilidade dos resultados relatados, assim como sua relevância e originalidade.

Tamanha foi a crença na revisão por pares, que agentes políticos, especialmente nos Estados Unidos, frequentemente falavam dela como o melhor método para se 
validar o conhecimento científico, mesmo quando este era produzido e utilizado em outros contextos - por exemplo, com o propósito de amparar políticas regulatórias. Na prática, uma abordagem tripartite, mais complexa, do controle de qualidade desenvolvido na maioria das democracias industriais - revisão por pares realizada por colegas da mesma disciplina na ciência básica; o desenvolvimento de boas práticas laboratoriais sob protocolos de pesquisa aplicáveis, tais como testes de produtos ou testes clínicos na pesquisa aplicada; e, por fim, a avaliação de risco para se avaliar as consequências ambientais e para a saúde da emissão de poluentes e produtos industriais. Mas, na medida em que cresceu a importância dos testes, pesquisas clínicas e avaliações de risco também aumentaram as demandas por sua confiabilidade científica. Novamente, a revisão por pares - ou seu análogo funcional, o aconselhamento independente de especialistas - era o mecanismo que os governos mais utilizavam para conseguir legitimação.

Os sinais de desgaste e ruptura no "contrato social" começaram a aparecer nos anos de 1980. Uma série de casos amplamente divulgados de supostas fraudes na ciência desafiaram a confiabilidade na revisão de pares e, com ela, os pressupostos subjacentes à autonomia da ciência. A ideia da unidade da ciência também começou a colapsar na medida em que se tornava claro que as pesquisas variavam de um contexto para o outro, não só nas diferentes disciplinas, mas nas diversas estruturas institucionais, o que é ainda mais relevante do ponto de vista da formulação de políticas. Foi reconhecido que a ciência regulatória, produzida para dar suporte às ações governamentais contra o risco, divergia fundamentalmente das pesquisas direcionadas pela curiosidade da comunidade científica. Ao mesmo tempo, observadores começaram a questionar se as categorias estabelecidas de pesquisa básica e aplicada apresentavam um significado em um mundo onde a produção e o uso da ciência estavam profundamente conectados entre si, assim como as suas consequências políticas e sociais mais amplas ${ }^{7}$. O esforço resultante para se redefinir o quadro de referência das interações entre ciência e sociedade compõe um importante pano de fundo para se apresentar tentativas de avaliar a accountability da pesquisa científica.

\section{A ciência na sociedade.}

\section{Novas avaliações}

As reflexões sobre as relações da ciência com a sociedade geraram três grandes correntes de análise. A primeira, embora aceite de modo não problemático o "contrato social", aponta suas falhas em funcionar tal como seus proponentes haviam inicialmente previsto. Muitos criticaram a ciência, em especial a ciência produzida nas universidades, por se desviar das normas mertonianas idealizadas de pureza
7. Para revisões da extensa e relevante literatura, ver Jasanoff, Markle, Petersen \& Pinch (1995). 
e desinteresse. Apesar - ou, talvez, por causa - de sua simplicidade conceitual, esta crítica afetou seriamente a credibilidade dos cientistas e suas reivindicações por autonomia. Outros observadores tentaram substituir a dicotomia entre ciência básica e aplicada por um modelo mais matizado, chamando a atenção para as peculiaridades da ciência em diferentes contextos e em relação a diferentes objetivos. Outros realizaram ambiciosos esforços para a redefinição do modo como o conhecimento científico passaria a ser produzido. Esta última linha de análise, em especial, não objetiva corrigir ou aprimorar a visão de ciência proposta por Vannevar Bush, antes almeja substituí-la por um relato mais complexo sobre como a produção de conhecimento se encaixa no funcionamento mais amplo da sociedade. Vejamos cada uma destas críticas.

\section{Ciência desviante}

Na década de 1980, fraudes científicas e condutas inadequadas se tornaram um problema na agenda política dos Estados Unidos. O interesse político atingiu o clímax com o notório caso de alegada conduta inadequada no laboratório do MIT dirigido pelo biólogo David Baltimore, o qual já havia sido laureado com o Prêmio Nobel de Medicina. Ele e seus colegas foram exonerados, mas apenas após anos de inquérito, os quais incluíram investigações feitas pelo Congresso e pelo Departamento Federal de Investigação (FBI) (Kevles, 1998). Este e outros episódios impulsionaram o aumento da supervisão sobre pesquisas por parte dos poderes federais consideravelmente ampliados e da elevada tendência de políticos e do público de suspeitarem que não estava tudo em ordem nas cidadelas da ciência básica. Houve quem considerasse o "caso Baltimore" um poderoso sinal da insatisfação dos legisladores com o antigo "contrato social", particularmente com o simples intercâmbio entre dinheiro e autonomia por benefícios tecnológicos (Guston, 2001).

Outros - como Daniel Greenberg, experiente jornalista científico - acusaram cientistas de lucrarem enormemente com sua aliança com o Estado, ao passo que não eram capazes de exercer autoridade moral ou influência significativa na formulação de políticas (Greenberg, 2001). Da ciência norte-americana, desde então, passou-se a pedir justificativas mais explícitas para a quantidade de dinheiro público gasto. Um sinal da nova relação entre ciência e sociedade foi a reforma realizada na década de 1990 sobre os critérios da Fundação Estadunidense de Ciência relativos à revisão por pares. A fundação passou a exigir que os pareceristas avaliassem propostas não apenas por méritos técnicos, mas também por implicações sociais mais amplas - conferindo, com isso, maior relevância à utilidade social. 
Com efeito, as próprias investigações públicas sobre as fraudes ocorridas na década anterior abriram para debate elementos da autonomia científica aceitos tacitamente e forçaram os cientistas a prestarem contas sobre os seus objetivos, assim como a defenderem sua honestidade.

A essas perturbações pode ser somado um constante fluxo de desafios ao suposto desinteresse da ciência acadêmica. De estudos das mudanças climáticas à biotecnologia, críticos acusaram cientistas de sacrificarem a objetividade em troca de financiamento para pesquisa, ou, ainda pior, de ações de lucrativas start-ups (Boehmer-Christiansen, 1994). Essas alegações foram especialmente prejudiciais para a biotecnologia, a qual se beneficia consideravelmente da rápida difusão de habilidades e conhecimentos. Em razão de a maioria dos governos ocidentais estar comprometida com a promoção de tais transferências, a biotecnologia se encontra presa em um dilema bem particular: como justificar suas promessas de inovação e progresso de modo verossímil quando os interesses da maioria dos cientistas estão inaceitavelmente alinhados com os da indústria, do governo ou - ocasionalmente dos advogados do "interesse público".

Como seria de se esperar, o viés conivente com os interesses da indústria foi o que atraiu o maior número de críticas. Apesar disso, pesquisadores acadêmicos também foram questionados por supostos vieses ambientalistas e antitecnologia. Em diversos casos envolvendo a biotecnologia - em particular o estudo sobre borboletas monarcas nos Estados Unidos conduzido pelo cientista John Losey, da Cornell University (Losey, Rayor \& Carter, 1999), e o controvertido estudo sobre a alimentação dos ratos realizado por Arpad Pusztai, no Reino Unido (Ewene \& Pusztai, 1999) -, membros da indústria questionaram a qualidade das pesquisas universitárias e afirmaram que posições políticas poderiam ter levado à precoce divulgação ou mesmo a interpretações infundadas dos resultados. Em abril de 2002, outra controvérsia semelhante emergiu a respeito de um artigo publicado na revista Nature, escrito por Ignacio Chapela, cientista da California University, no qual ele argumentava que milho geneticamente modificado tinha contaminado espécies nativas no México. O respeitado editor do periódico - Philip Campbell - não retirou o artigo, mas afirmou que "as evidências disponíveis não eram suficientes para a publicação do documento original" e que os leitores deveriam "julgar a ciência por si mesmos" (Campbell, 2002). Tal como nos casos de Losey e Pusztai, os críticos acusaram o trabalho de Chapela de ser enviesado por considerações não científicas. Não obstante, os ambientalistas consideraram esses episódios como sinal de um completo déficit de conhecimento sobre os efeitos sistêmicos de longo prazo da modificação genética em plantas de cultivo. 


\section{Ciência de contexto específico}

A segunda linha de ataque, na relação entre ciência e sociedade, concentra-se na distinção ciência básica versus ciência aplicada. Uma tentativa de sair do dualismo simplista foi proposta por Donald Stokes (1997), cuja abordagem, ao utilizar Louis Pasteur como protótipo, sugeriu que a ciência "básica" pode ser feita dentro de contextos altamente "aplicados". Historiadores e sociólogos da ciência e tecnologia já observaram, há muito tempo, que o trabalho de base pode ser feito em conexão com problemas aplicados, assim como a resolução de problemas aplicados pode ser usada para resolver problemas teóricos (por exemplo, no design de novos instrumentos científicos). Até agora, as formulações baseadas em tais descobertas têm demorado a criar raízes nas culturas políticas. O interessante no trabalho de Stokes não é apenas a originalidade de suas ideias, mas a tentativa de trazer fatos históricos para se conectarem com as categorias de análise da políticas relacionadas à ciência.

Assim como Vannevar Bush, Donald Stokes estava mais interessado na promoção da inovação do que em seu controle. Como aumentar a supervisão democrática da ciência não era sua principal preocupação. Não surpreendentemente, a accountability da ciência surgiu como um tema forte em estudos de risco e regulação, arena em que os governos buscam ativamente administrar os aspectos potencialmente prejudiciais do progresso tecnológico. Aqui, também, há tentativas de caracterizar a ciência como algo mais do que simplesmente "básica" ou "aplicada".

A partir de seus conhecimentos em filosofia da ciência, Silvio Funtowicz e Jerome Ravetz (1992: 251-273) propuseram dividir o mundo da ciência relevante do ponto de vista político em três dimensões, cada qual com seu próprio sistema de controle de qualidade:

i. "ciência normal" (tomando emprestado o conhecido conceito de Thomas Kuhn), para pesquisas científicas comuns;

ii. "consultoria profissional", aplicação do conhecimento disponível a problemas bem definidos; e

iii. "ciência pós-normal" (conhecimento altamente incerto e contestado), necessário para muitas decisões relacionadas à saúde, à segurança e ao meio ambiente.

Esses autores observaram que, ao passo que a tradicional revisão por pares pode ser efetiva dentro da "ciência-normal", ou mesmo dentro da "consultoria profis- 
sional", a qualidade da ciência "pós-normal" não pode ser assegurada unicamente pelo processo de revisão padrão. Ao invés disso, propuseram que trabalhos desta natureza fossem submetidos a um processo ampliado de revisão por pares, envolvendo não só cientistas, mas também as partes interessadas que são afetadas pelo uso da ciência. Dito de outro modo: consideraram a accountability, ao invés do mero controle de qualidade, como o objetivo desejado quando a ciência se torna "pós-normal"8.

O estudo de Jasanoff de 1990 sobre comitês consultivos de especialistas nos Estados Unidos observou que a ciência politicamente relevante (também referida como "ciência regulatória"), a exemplo da ciência realizada para fins de avaliação de risco, é frequentemente submetida ao que os formuladores de políticas chamam de "revisão pelos pares" (Jasanoff, 1990). Se o examinarmos, esse exercício difere fundamentalmente da revisão da ciência nas formas convencionais de pesquisa. A ciência regulatória é revista por comitês multidisciplinares e não por especialistas selecionados individualmente. O papel de tais comitês não é apenas validar os métodos pelos quais os riscos são identificados e investigados, mas também atestar a confiabilidade da interpretação da evidência pela agência.

Frequentemente, a ciência regulatória confronta a necessidade de estabelecer padrões para objetos ou conceitos cuja própria existência não havia sido antes uma questão tanto para a ciência como para as políticas públicas: o "material particulado fino", no controle da poluição do ar; a "dose máxima tolerada", em bioensaios; a "pessoa mais exposta", em relação aos tóxicos no ar; ou a "melhor tecnologia disponível", em muitos programas de regulação ambiental. Ao especificar como tais termos devem ser definidos e caracterizados, os comitês consultivos devem abordar problemas que são tanto técnicos como sociais, tanto científicos como normativos, regulatórios como metafísicos. O tipo de entidade é, afinal, um material particulado "fino" ou uma pessoa "mais exposta", e por quais marcadores podemos reconhecê-los? Estudos de ciência regulatória mostraram que o poder dos comitês consultivos para abordar tais problemas de modo definitivo depende inteiramente de sua probidade, representatividade, transparência e abertura para prestar contas a uma autoridade maior - como os tribunais e o público. Em outras palavras, a credibilidade da ciência regulatória depende, em última instância, de fatores que têm mais a ver com a accountability em termos de políticas democráticas do que com a qualidade da ciência avaliada por pares da comunidade científica.

Nas sociedades industriais modernas, os estudos destinados a estabelecer a segurança ou a efetividade das novas tecnologias são frequentemente delegados aos
8. Um problema dessa análise reside no conceito "ciência pós-normal". Quando uma conclusão científica está intimamente entrelaçada com considerações sociais e normativas, pode-se igualmente chamar o "produto" por outro nome como "conhecimento socialmente relevante" ou "conhecimento sociotécnico". 
produtores. Processos de controle de qualidade para testes de produtos dentro da indústria incluem a imposição e aplicação de boas práticas laboratoriais, sob supervisão das agências reguladoras e de seus consultores científicos. A extensão precisa do custo da produção de conhecimento na indústria é muitas vezes negociada com as agências regulatórias e pode ser afetada por considerações econômicas e políticas que não são instantaneamente visíveis para as pessoas de fora (a definição de dose máxima tolerada para bioensaios é um exemplo bem conhecido). Limitações de recursos podem restringir as auditorias e inspeções estatais de laboratórios da indústria, levando a problemas de controle de qualidade, enquanto as cláusulas que impedem informações comerciais confidenciais de serem divulgadas podem reduzir a transparência da pesquisa relacionada a produtos e a processos específicos conduzidas pela indústria. Por fim, os limites da imaginação do regulador colocam limitações significativas à obrigação da indústria de gerar informação. Apenas na esteira de desastres ambientais envolvendo dioxina, isocianato de metilo e bifenilpoliclorado, e logo após a exposição acidental de populações e ecossistemas, foram descobertas lacunas nas informações disponíveis sobre os efeitos crônicos e de longo prazo de muitos produtos químicos perigosos. Antes de o desastre acontecer, os reguladores não reconheciam a necessidade de tais informações. Ocorrências como essas levaram a demandas por esforços de maior accountability por parte da ciência do que aquela produzida tão somente para amparar a regulação.

\section{Novos modos de produção do conhecimento}

Para além das questões de qualidade e da dependência do contexto específico, alguns sugeriram que deveríamos examinar com novos olhos as características estruturais da ciência, a fim de torná-la socialmente mais responsiva. Michael Gibbons e seus coautores (Gibbons, Limoges, Nowotny, Schwartzman, Scott \& Trow, 1994) concluíram que a tradicional ciência disciplinar de Bush foi amplamente suplantada por um novo "Modo 2" de produção de conhecimento. As propriedades mais destacadas desse novo modo, na opinião de seus proponentes, incluem a seguintes características:

口 o conhecimento é cada vez mais produzido em contextos de aplicação (ou seja, toda ciência é, em certa medida, "ciência aplicada");

- a ciência é cada vez mais transdisciplinar (isto é, baseia-se e integra elementos empíricos e teóricos de uma variedade de campos);

- o conhecimento é gerado em uma maior variedade de locais do que em qualquer período no passado, não apenas nas universidades e na 
indústria, mas também em outros tipos de centros de pesquisa, consultorias e think-tanks; e

a os cientistas tornaram-se mais conscientes das implicações sociais de seu trabalho (ou seja, mais "reflexivos"), assim como o público se tornou mais consciente das formas como a ciência e a tecnologia afetam seus interesses e valores.

O crescimento da ciência de "Modo 2", como Gibbons et alii notam, tem implicações necessárias para o controle de qualidade. Além de antigas questões sobre os méritos intelectuais de seu trabalho, os cientistas estão sendo chamados a responder perguntas sobre a comerciabilidade e a capacidade da ciência de promover a harmonia social e o bem-estar. Assim:

A qualidade é determinada por um conjunto mais amplo de critérios, que reflete a ampliação da composição social do sistema de revisão por pares. Isso implica que a "boa ciência" é mais difícil de definir, uma vez que não está mais limitada aos julgamentos dos pares da mesma disciplina. O medo é que o controle será mais fraco e resulte em um trabalho de menor qualidade. Embora o processo de controle de qualidade no Modo 2 seja mais amplamente baseado, isso não significa [...] que será necessariamente de menor qualidade (Gibbons, Limoges, Nowotny, Schwartzman, Scott \& Trow, 1994: 8).

Um aspecto importante desta análise é que, na ciência de "Modo 2", o controle de qualidade, para fins práticos, fundiu-se com a accountability. Gibbons et alii veem toda a ciência como cada vez mais firmada na - e, portanto, mais responsável diante da - sociedade em geral. Continuar insistindo em um espaço separado para a pesquisa básica com medidas autônomas para o controle de qualidade parece ser, dentro de seu quadro teórico, uma relíquia de uma era anterior.

Em um trabalho mais recente, Helga Nowotny, Peter Scott e Michael Gibbons lidaram com as implicações dessas mudanças na produção de conhecimento em domínio público (Nowotny, Scott \& Gibbons 2001: 166-178). Diferentemente do modelo tubular, no qual a ciência gerada por instituições de pesquisa independentes eventualmente alcançam a indústria e o governo, Nowotny et alii propõem o conceito de "conhecimento socialmente robusto" como solução para problemas de conflito e de incerteza. A contextualização, na opinião dos autores, é a chave para a produção de ciência para fins públicos. A ciência que extrai sua força de uma posição de distanciamento da sociedade é muito frágil para enfrentar as pressões colocadas sobre ela pelas sociedades contemporâneas. Em vez disso, 
Nowotny et alii imaginam formas de conhecimento que obteriam robustez de sua própria inserção na sociedade. O problema, naturalmente, é como institucionalizar processos de produção de conhecimento policêntricos, interativos e formados por múltiplas partes em instituições que têm trabalhado por décadas para manter conhecimentos técnicos longe dos caprichos do populismo e da política. A questão com a qual a governança da ciência se confronta é como levar o público bem informado à linha de frente da produção científica e tecnológica - um lugar do qual esse mesmo público foi historicamente estritamente excluído.

\section{A virada participativa}

Transformações nos modos de pesquisa científica e desenvolvimento fornecem pelo menos uma explicação parcial para o atual interesse em melhorar o acesso público à tomada de decisões de experts. Ao pensar na pesquisa hoje, formuladores de políticas e o público inevitavelmente focam na accountability da ciência. Na medida em que as relações da ciência se tornaram mais difusas, dinâmicas e heterogêneas, as preocupações com a integridade da revisão pelos pares se transmutaram em demandas por um maior envolvimento público na avaliação de custos e benefícios, bem como dos riscos e das incertezas das novas tecnologias. Essas demandas surgiram com especial urgência no caso da biotecnologia, mas elas não se limitam de modo algum a esse campo.

A pressão por accountability manifesta-se de muitas maneiras, sendo a demanda por maior transparência e participação talvez a mais proeminente dentre elas. Um exemplo notável veio com a legislação federal dos Estados Unidos, em 1998, ao

9. Public Law, 1998: 105-277. A Secretaria de Gestão e Orçamento do governo Clinton restringiu, de modo controverso, o escopo da lei para se aplicar não a todas as pesquisas financiadas com recursos públicos, mas apenas a pesquisas das quais a formulação de políticas realmente depende. A questão não havia ainda sido completamente resolvida durante a redação deste artigo. se exigir acesso público a toda pesquisa científica fomentada por fundos públicos, conforme a Lei de Liberdade de Informação ${ }^{9}$. Essa cláusula foi apresentada apressadamente e insuficientemente discutida. Seu proponente, senador Richard Shelby (republicano do estado do Alabama), anexou-a como emenda de última hora à Lei Orçamentária Anual. Seu objetivo imediato era forçar a divulgação dos dados pela Escola de Saúde Pública de Harvard de um estudo controverso de efeitos sobre a saúde da exposição humana a partículas finas. O chamado "Estudo de seis cidades" forneceu uma justificativa chave para o rigoroso padrão ambiental da Agência de Proteção Ambiental dos Estados Unidos para partículas de matéria em suspensão no ar, publicado em 1997. A despeito de suas motivações políticas, essa emenda mostrou que o Congresso não estava mais disposto a conceder autonomia sem controle à comunidade científica na coleta e interpretação de dados, especialmente quando os resultados poderiam influenciar ações regulatórias de alto custo. A ciência financiada pelo governo - determinou o Congresso - deveria estar integralmente disponível a todo momento para processos de revisão públicos. 
Tradições de participação são menos institucionalizadas na política europeia, mas mudanças recentes nas regras que regem os pareceres dos especialistas mostram um compromisso crescente em envolver o público em decisões tecnicamente fundamentadas. Ao anunciar a criação de um novo Diretório Geral para a Defesa do Consumidor, a Comissão Europeia observou, em 1997, que

\begin{abstract}
a confiança dos consumidores nas atividades legislativas da União Europeia está condicionada pela qualidade e transparência do parecer científico e por seu uso nos processos legislativos e de controle (Comissão Europeia, 1997: 183, destaques da autora).
\end{abstract}

Um compromisso com uma maior abertura também é evidente em vários novos órgãos de especialistas do Reino Unido, como a Agência de Padrões para Alimentos, criada para restaurar a confiança durante a emergência da crise da "doença da vaca louca". De modo similar, dois grandes inquéritos públicos - o Inquérito Phillips, sobre a "doença da vaca louca", e o Inquérito Smith, sobre a investigação do assassinato de Harold Shipman - estabeleceram padrões elevados para o acesso público à informação através da Internet. Em toda a Europa, a oposição a alimentos e culturas geneticamente modificados deu origem a experimentos com diversas formas de envolvimento público, tais como júris cidadãos, conferências de consenso e referendos (Joss \& Durant, 1995).

Embora esses esforços sejam admiráveis, oportunidades de participação formais não podem por si só assegurar a governança representativa e democrática da ciência. Há, de início, problemas práticos. A população pode não apresentar conhecimentos especializados ou recursos materiais adequados para se aproveitar dos procedimentos formais. A participação pode ocorrer muito tarde para identificar alternativas às opções dominantes ou padrão; alguns processos, tais como as conferências de consenso, podem ser muito ad hoc ou específicos sobre um assunto para exercer influência continuada. Mais problemático é o fato de que mesmo em tempo hábil, a participação não necessariamente melhora a tomada de decisões. Pesquisas empíricas têm constantemente mostrado que a transparência pode exacerbar controvérsias, em vez de abrandá-las, levando as partes a desconstruírem as posições umas das outras ao invés de deliberarem efetivamente. De fato, a emenda Shelby reflete a convicção de um político dos Estados Unidos de que a divulgação compulsória de dados permitirá que qualquer parte interessada questione as interpretações dos pesquisadores. A participação, neste sentido, se torna um instrumento para desafiar opiniões científicas com base em posições políticas. Por outro lado, a participação pública que é restringida por discursos formais estabelecidos - tal como a avaliação de riscos - pode não admitir novos pontos de vista, críticas radicais ou considerações que se apoiem fora do enquadramento padrão do problema. 
10. Em 1998, uma pequena empresa de sementes de algodão chamada Delta and Pine Land (D\&PL) patenteou uma técnica projetada para suspender o mecanismo de reprodução de plantas, tornando a semente esterilizada. A empresa esperava que essa tecnologia ajudasse a proteger os direitos de propriedade intelectual das empresas de biotecnologia agrícola, ao tirar dos agricultores a capacidade de reutilizar as sementes das culturas geneticamente modificadas de um determinado ano para o outro. Enquanto a tecnologia ainda estava longe do mercado, surgiram rumores de um acordo da Monsanto para adquirir a D\&PL. Este foi o cenário que levou a Rural Advancement Foundation International a agir (Ver: Service, 1998).
Enquanto os governos nacionais estão se apressando para criar novas formas de participação, há sinais de que tais mudanças podem não ter o alcance suficiente, nem a profundidade satisfatória para persuadir os cidadãos de um mundo globalizado. As reformas atuais deixam de lado o envolvimento público na tomada de decisões de corporações nas fases de design e desenvolvimento do produto. A experiência da Monsanto com o "gene Terminator" sugere que os ativistas políticos podem tomar o controle das decisões em seus próprios termos a menos que estruturas de governança proporcionem uma participação mais deliberativa. Nesse caso, a mera possibilidade de que uma poderosa corporação multinacional possa adquirir tecnologia para destituir pobres agricultores de seus direitos estimulou uma organização ativista - a Fundação Internacional para o Avanço Rural (Rural Advancement Foundation International - Rafi) - a lançar uma campanha mundial efetiva contra a tecnologia ${ }^{10}$. Através de uma combinação de táticas midiáticas inspiradas (como dar um nome à tecnologia inspirado em um popular filme de ficção científica) e da construção estratégica de alianças - com a Fundação Rockefeller, por exemplo -, a Rafi forçou a Monsanto a desistir deste produto específico. O episódio pode ser entendido como um caso de avaliação popular da tecnologia em um contexto em que os processos oficiais não conseguiram proporcionar o nível de accountability desejado pelo público.

A participação por si só, portanto, não resolve o problema da democratização das sociedades tecnológicas. Abrir as portas de fóruns de especialistas previamente fechados é um passo necessário - de fato, isso já deveria ser visto como um procedimento operacional padrão. Mas os mecanismos formais adotados pelos governos nacionais não são suficientes para envolver o público na gestão das ciências e tecnologias globais. O que tem de mudar é a cultura da governança, tanto dentro das nações como em escala internacional; e, para isso, precisamos abordar não só a mecânica, mas também a substância da política participativa. A questão, em outras palavras, não é mais se o público deve ter voz nas decisões técnicas, mas como promover uma interação mais significativa entre os formuladores de políticas públicas, os experts científicos, os produtores empresariais e o público.

\section{Tecnologias da humildade}

A engenhosidade analítica dos Estados modernos tem sido direcionada para o refinamento daquilo que poderíamos chamar de "tecnologias da húbris". Para tranquilizar o público e para manter o desenvolvimento da ciência e da indústria, os governos têm desenvolvido uma série de métodos de previsão (por exemplo: avaliação de riscos, análises de custo-benefício, modelagem climática) que são elaborados, de modo geral, para facilitar o controle e gerenciamento, mesmo em áreas de grande 
incerteza (Porter, 1995). Estes métodos obtêm seu poder por meio da reivindicação de objetividade e de uma abordagem analítica disciplinada, mas sofrem de três limitações significativas.

- Em primeiro lugar, apresentam uma espécie de cegueira periférica no que diz respeito à incerteza e à ambiguidade. Métodos de previsão privilegiam o conhecido em detrimento do desconhecido produzindo uma confiança exagerada na completude ou acurácia das imagens que produzem. Riscos bem definidos e de curto prazo exigem mais atenção do que os indeterminados de longo prazo, especialmente em culturas dadas ao otimismo tecnológico. Ao mesmo tempo, a proficiência técnica transmite a falsa impressão de que a análise é não apenas rigorosa, mas completa - em suma, que levou em conta todos os riscos possíveis. Métodos de previsão tendem desse modo a minimizar aquilo que está fora de seu campo de visão e a dar excessiva ênfase àquilo que esteja dentro (Irwin \& Wynne, 1996).

- Em segundo lugar, as tecnologias de análise preditiva tendem a impedir a discussão política. Os quadros de referência dos experts criam grandes barreiras contra posicionamentos legítimos que não conseguem se expressar nos termos do discurso dominante (Winner, 1986). Reivindicações de objetividade escondem o exercício do julgamento, de modo que os pressupostos normativos não estão sujeitos ao debate aberto. O trabalho de demarcação que define o espaço da análise de políticas "objetivas" é levado a cabo pelos experts, de modo que as políticas de demarcação permanecem interditadas à crítica e ao debate públicos (Jasanoff, 1990).

- Em terceiro lugar, as tecnologias preditivas são limitadas em sua capacidade de internalizar desafios que surgem fora das premissas estabelecidas pelo seu quadro de referência. Por exemplo, técnicas para avaliação de toxicidade química têm se tornado cada vez mais refinadas, mas continuam a repousar sobre a falsa premissa de que pessoas são expostas a uma única substância por vez. Efeitos sinergísticos, exposições a longo prazo e múltiplas exposições são comuns na vida cotidiana, mas tendem a ser ignoradas como caóticas demais para serem analisadas, logo, como irrelevantes para tomadas de decisão. Mesmo depois de falhas catastróficas, os modelos preditivos da modernidade são frequentemente ajustados para levar em conta apenas aquelas lições que são compatíveis com suas premissas 
iniciais. Quando em uma fábrica de químicos norte-americana em Bhopal, na Índia, houve um vazamento de metil isocianato, um gás mortal que acabou matando milhares de pessoas, a indústria química internacional realizou vários avanços em suas práticas internas de accountability e comunicação de riscos. No entanto, nenhum novo método foi desenvolvido para avaliar os riscos da transferência de tecnologia entre culturas de produção industrial radicalmente diferentes.

Até hoje os aspectos desconhecidos, inespecíficos e indeterminados do desenvolvimento científico e tecnológico permanecem largamente ignorados em se tratando de formulação de políticas públicas; tratados como imponderáveis, eles escapam ao rigor da análise. Todavia, o que falta não é apenas o conhecimento para preencher as lacunas, mas também métodos e processos para trazer à tona a vontade do público e para utilizar o que já se conhece. Para que essas dimensões possam fazer parte do debate democrático, deve-se primeiro torná-las concretas e tangíveis. Conhecimentos privados e dispersos têm de ser amalgamados, talvez até disciplinados, em uma epistemologia cívica confiável. As ciências sociais e humanas dos séculos anteriores empreenderam justamente esta tarefa de tradução. Elas tornaram visíveis os problemas sociais da modernidade - pobreza, desemprego, criminalidade, doença e, mais recentemente, riscos tecnológicos - frequentemente como prelúdio à sua transformação em algo mais gerenciável, usando o que eu tenho chamado de "tecnologias da húbris". Há hoje uma necessidade de "tecnologias da humildade" para complementar as abordagens preditivas:

๑ para evidenciar a possibilidade de consequências não previstas;

u para tornar explícito o caráter normativo que se esconde por detrás da técnica; e

a para reconhecer desde o início a necessidade de uma pluralidade de pontos de vista e de aprendizado coletivo.

De que maneira esses objetivos poderiam ser alcançados? A partir da abundante literatura a respeito das falhas e dos desastres tecnológicos, assim como de estudos de análise de risco e ciência relevante para a formulação de políticas, podemos abstrair quatro pontos focais em torno dos quais somos capazes de desenvolver novas tecnologias da humildade. São eles: enquadramento, vulnerabilidade, distribuição e aprendizagem. Juntos, eles podem fornecer um enquadramento para as questões que deveriam ser feitas a praticamente qualquer empreendi- 
mento humano que pretenda alterar a sociedade: qual é seu propósito; quem será prejudicado; quem será beneficiado; e como podemos sabê-lo? Em todos estes pontos temos boas razões para acreditar que um engajamento público mais amplo poderia melhorar nossa capacidade de análise e reflexão. Uma participação que preste atenção a estes quatro pontos promete não levar nem a um endurecimento das posições, nem a uma infindável desconstrução, mas, ao invés disso, a uma deliberação mais rica sobre a substância da tomada de decisão.

- Enquadramento - Já se tornou artigo de fé na literatura sobre políticas públicas que a qualidade das soluções para problemas sociais dependem da maneira como são enquadrados (Schon \& Rain, 1994). Se um problema é enquadrado de maneira muito estreita, muito ampla ou erroneamente, a solução sofrerá com essas distorções. Para tomar um exemplo simples, uma política sobre testes químicos focada em um único elemento não pode produzir conhecimento acerca das implicações ambientais de exposições a múltiplas substâncias. O enquadramento das questões regulatórias é mais restritivo do que a real distribuição dos riscos quimicamente induzidos, sendo assim incapaz de proporcionar estratégias ótimas de gerenciamento. De modo semelhante, a crença de que a violência seja genética pode desencorajar a busca por influências sociais controláveis sobre o comportamento. Um foco na biologia da reprodução pode atrasar ou impedir políticas sociais efetivas para reduzir o crescimento populacional. Quando os fatos são incertos, desacordos acerca do enquadramento apropriado são virtualmente inevitáveis e frequentemente permanecem insolúveis por longos períodos. Ainda assim, poucas culturas políticas têm adotado métodos sistemáticos para revisar o enquadramento inicial dos problemas (Stern \& Fineberg, 1995). Análises de enquadramento permanecem assim uma ferramenta de extrema importância - ainda que negligenciada - para a formulação de políticas que se beneficiariam de uma maior participação pública.

- Vulnerabilidade - A análise dos riscos trata o ser humano em risco como um agente passivo no meio do caminho de eventos potencialmente desastrosos. Em um esforço de produzir avaliações politicamente relevantes, populações humanas são frequentemente classificadas em grupos (por exemplo, mais suscetíveis, maximamente expostos, geneticamente predispostos, mulheres ou crianças) que são entendidos como afetados de forma diferente pelo risco em questão. Sendo baseadas em indicadores físicos e biológicos, essas 
classificações tendem, no entanto, a subestimar as bases sociais da vulnerabilidade e a subordinar experiências de risco individuais a um conjunto de cálculos e números (Irwin \& Wynne, 1996). Os esforços recentes de se analisar a vulnerabilidade têm começado a reconhecer a importância dos fatores socioeconômicos, mas métodos de avaliação ainda utilizam populações, ao invés de indivíduos, como unidade de análise. Estas abordagens não apenas desconsideram as diferenças existentes entre os grupos, como também reduzem os indivíduos a representações estatísticas. Tais caracterizações deixam de fora do cálculo de vulnerabilidade fatores como história, lugar e conectividade social, os quais podem desempenhar papéis fundamentais para a determinação da resiliência humana. Através da participação na análise de sua vulnerabilidade, cidadãos comuns podem reaver seu status de sujeitos ativos, ao invés de permanecerem como objetos indiferenciados em mais um discurso de experts.

- Distribuição - Controvérsias a respeito de inovações como alimentos geneticamente modificados e pesquisas com células tronco têm empurrado os comitês de ética para debates nos níveis mais altos da formulação de políticas. No entanto, estas entidades são frequentemente usados como dispositivos de legitimação de última instância, garantindo ao público que questões normativas não foram omitidas da deliberação governamental. Além disso, o termo "ética" não cobre todo o espectro de realinhamentos sociais e econômicos que acompanham grandes mudanças tecnológicas, nem suas consequências distributivas, particularmente quando a tecnologia se desenrola pelas sociedades e pelos mercados globais. Tentativas de engajamento sistemático com questões distributivas em processos políticos, de modo geral, não têm tido sucesso. Na Europa, as considerações acerca do "quarto obstáculo" - o impacto socioeconômico da biotecnologia - foram abandonadas após um curto debate. Nos Estados Unidos, o Escritório de Avaliação da Tecnologia do Congresso, que teria supostamente o dever de avaliar impactos socioeconômicos, foi dissolvido em 1995 (Bimber, 1996). A injunção de 1994, do presidente Clinton, para que as agências federais desenvolvessem estratégias para alcançar a justiça ambiental, produziu alguns poucos resultados de maior impacto (Executive Order 12298, 1994). Ao mesmo tempo, episódios como a rebelião liderada pela Rafi contra a Monsanto demonstram um déficit na capacidade para a análise ética e política em grandes corporações cujos produtos tecnológicos 
podem alterar fundamentalmente as vidas das pessoas. Interações contínuas entre tomadores de decisão, especialistas e cidadãos, começando nos momentos iniciais da pesquisa e do desenvolvimento, poderiam proporcionar dividendos significativos ao explicitar as implicações distributivas da inovação.

- Aprendizagem - Teóricos da aprendizagem social e institucional tendem a assumir que o que "deve ser aprendido" nunca é parte do problema. Existe uma resposta correta, ou pelo menos melhor, e a questão é se os atores estão ou não preparados para internalizá-la. No mundo social, a aprendizagem é complicada por vários fatores. A capacidade de aprender é restringida pelos fatores limitantes do quadro de referência dentro do qual as instituições devem agir. Instituições veem apenas o que seus discursos e práticas permitem enxergar. Além disso, a experiência é polissêmica, ou sujeita a muitas interpretações, tanto na formulação de políticas quanto em textos literários. Mesmo quando a falha em um determinado caso é mais ou menos inequívoca, suas causas podem estar abertas a muitas diferentes leituras. Assim como historiadores discordam sobre o que pode ter causado a ascensão ou queda de um regime político em particular, também os formuladores de políticas podem considerar impossível atribuir suas falhas a causas específicas. As origens de um problema podem aparecer de uma forma para aqueles que estão no poder e de outra bem diferente para aqueles que são marginalizados ou excluídos. Ao invés de procurar por explicações monocausais, seria mais proveitoso desenvolver caminhos pelos quais as sociedades pudessem refletir coletivamente sobre a ambiguidade de suas experiências e avaliar os pontos fortes e fracos de explicações alternativas. A aprendizagem, nesse sentido modesto, é um objetivo adequado para a deliberação cívica.

\section{Conclusão}

O enorme crescimento e sucesso da ciência e tecnologia durante o último século criou contradições para as instituições de governança. Na medida em que as atividades técnicas se tornaram cada vez mais onipresentes e complexas, cresceu a demanda por avaliações mais completas e multivalentes dos custos e benefícios do progresso tecnológico. Já é amplamente reconhecido que uma construção de conhecimento mais interativa e participativa pode aumentar a accountability e levar a avaliações de maior credibilidade sobre ciência e tecnologia. Essas abor- 
dagens serão também consistentes com as mudanças nos modos de produção do conhecimento, que fizeram com que a ciência se tornasse socialmente mais enraizada e mais atrelada aos contextos de sua aplicação. Ainda assim, as instituições modernas ainda operam utilizando modelos conceituais que procuram separar a ciência dos valores e enfatizam a previsão e o controle em detrimento da reflexão e do aprendizado social. Não é surpreendente que o mundo real continuamente produza lembretes sobre a incompletude de nossas capacidades preditivas através de trágicos choques como os "acidentes normais" de Perrow.

Um desenvolvimento promissor é a atenção renovada que está sendo dada à participação e à transparência. Tal participação - como tenho argumentado - deveria ser tratada como um procedimento normal da democracia, mas seus objetivos devem ser considerados com tanto cuidado quanto seus mecanismos. Procedimentos formalmente constituídos não necessariamente incluem todos aqueles cujo conhecimento e cujos valores são essenciais para a formulação de políticas progressistas. A participação na ausência da discussão normativa pode levar a conflitos insolúveis do tipo encontrado no debate sobre políticas a respeito das mudanças climáticas. Do mesmo modo, a preocupação quase exclusiva de formuladores de políticas contemporâneos com o gerenciamento e controle do risco não deixa muito espaço para debates complexos sobre futuros tecnológicos, sem os quais estamos condenados a repetir os erros do passado.

Ao levar a discussão pública sobre ciência e tecnologia para novos rumos, sugeri a necessidade de "tecnologias da humildade", complementando as "tecnologias da húbris" preditivas, com as quais temos despendido tanto da nossa atenção até o momento. Essas tecnologias sociais dariam atenção combinada à substância e ao processo e enfatizariam tanto a deliberação como a análise. Ao reverter praticamente um século de desenvolvimento contrário, essas abordagens sobre a tomada de decisão deveriam buscar integrar a orientação do "poder fazer" da ciência e engenharia com as questões relacionadas ao "dever fazer" das análises éticas e políticas. Elas engajariam o sujeito humano como agente ativo, imaginativo, assim como uma fonte de conhecimento, insight e memória. Os pontos focais específicos que propus - enquadramento, vulnerabilidade, distribuição e aprendizagem - são seixos jogados em um poço, com força ainda não testada e resultando em ondas imprevisíveis. Estes conceitos em particular podem se mostrar insuficientes para conduzir mudanças institucionais sérias, mas eles podem pelo menos oferecer pontos de partida para um debate público mais profundo sobre o futuro da ciência na sociedade. 


\section{Referências}

BECK, Ulrich. Risk society: towards a new modernity. London: Sage, 1992.

BIMBER, Bruce. The politics of expertise in Congress: the rise and fall of the Office of Technology Assessment. Albany (NY): State University of New York Press, 1996.

BOEHMER-CHRISTIANSEN, Sonja. Global climate protection policy: the limits of scientific advice, parts 1 and 2. Global Environmental Change, v. 4, n. 2, p. 140-159, 1994; v. 4, n. 3, p. 185-200, 1994.

BUSH, Vannevar. Science - the endless frontier. Washington (DC): US Government Printing Office, 1945.

CAMPBELL, Philip. Nature regrets publication of corn study. The Washington Times, 5 Apr. 2002. Disponível em: <http://www.washingtontimes. com/national/200 20405-9384015.htm>.

CLARKE, Lee. Acceptable risk? Making decisions in a toxic environment. Berkeley (CA): University of California Press, 1989.

COMISSÃO EUROPEIA. Comunicação da Comissão Europeia sobre saúde e segurança do consumidor, p. 183, 1997, COM (97). Disponível em: <http://europa.eu.int/ comm/food/fs/sc/index_en.htmls.

EXECUTIVE ORDER 12298. "Federal actions to address enviromental justice in minority populations and low-income populations". Washington (DC): White House, 11 Feb. 1994.

FUNTOWICZ, Silvio O.; Ravetz, Jerome R. Three types of risk assessment and the emergence of post normal science. In: KRIMSKYE, Sheldon; GOLDING, Dominic (Orgs.). Social theories of risk. New York: Praeger, 1992.

EWENE, Stanley W. B.; PUSZTAI, Arpad. Effect of diets containing genetically modified potatoes expressing Galanthusnivalis lectin on rat small intestine. Lancet, $\mathrm{n}$. 354, p. 1353-1354, 1999.

GIBBONS, Michael; LIMOGES, Camille; NOWOTNY, Helga; SCHWARTZMAN, Simon, SCOTT, Peter; TROW, Martin. The new production of knowledge: the dynamics of science and research in contemporary societies, London: Sage, 1994.

GRAHAM, John D.; WIENER, Jonathan B. (Orgs.). Risk versus risk: tradeoffs in protecting health and the environment, Cambridge (MA): Harvard University Press, 1995. 
GREENBERG, Daniel S. Science, money, and politics: political triumph and ethical erosion, Chicago (IL): University of Chicago Press, 2001.

GUSTON, David H. Between politics and science: assuring the integrity and productivity of research. Cambridge (UK): Cambridge University Press, 2001.

IRWIN, Alan; WYNNE, Brian (Orgs.). Misunderstanding science? The public reconstruction of science and technology. Cambridge (UK): Cambridge University Press, 1996.

JASANOFF, Sheila. The fifth branch: science advisers as policy-makers, Cambridge (MA): Harvard University Press, 1990.

JASANOFF, Sheila; MARKLE, Gerald E.; PETERSEN, James C.; PINCH, Trevor (Orgs.). Handbook of science and technology studies. Thousand Oaks (CA): Sage, 1995.

JOSS, Simon; DURANT, John (Ed.). Public participation in science: the role of consensus conferences in Europe. London: Science Museum, 1995.

KEVLES, Daniel J. The Baltimore case: a trial of politics, science, and character. New York: Norton, 1998.

LOSEY, John E.; RAYOR, L. S.; CARTER, M. E. Transgenic Pollen Harms Monarch Larvae. Nature, n. 399, 1999.

NOWOTNY, Helga; SCOTT, Peter; GIBBONS, Michael. Re-thinking science: knowledge and the public in an age of uncertainty. Cambridge (UK): Polity, 2001.

PERROW, Charles. Normal accidents: living with high risk technologies. New York: Basic Books, 1984.

PORTER, Theodore M. Trust in numbers: the pursuit of objectivity in science and public life. Princeton (NJ): Princeton University Press, 1995.

PRICE, Don K. The scientific estate. Cambridge (MA): Harvard University Press, 1965. SERVICE, Robert F. Seed-sterilizing "Terminator Technology" sows discord. Science, n. 282, p. 850-851, 1998.

SCHON, Donald A.; REIN, Martin. Frame reflection: toward the resolution of intractable policy controversies. New York: Basic Books, 1994.

SHORT, James F.; CLAKE, Lee (Eds.). Organizations, uncertainties, and risk. Boulder (CO): Westview Press, 1992. 
STERN, Paul C.; FINEBERG, Harvey V. (Eds.). Understanding risk: informing decisions in a democratic society. Washington (DC): National Academy of Science Press, 1995.

STOKES, Donald E. Pasteur's quadrant: basic science and technological innovation. Washington (DC): Brookings Institution, 1997.

VAUGHAN, Diane. The challenger launch decision: risk technology, culture, and deviance at Nasa. Chicago (IL): University of Chicago Press, 1996.

WINNER, Langdon. On not hitting the tar baby. In: WINNER, Langdon (Org.). The whale and the reactor: a search for limits in an age of high technology, p. 138-154. Chicago (IL): University of Chicago Press, 1986. 
